Article

\title{
Industrial Pollution Control and Efficient Licensing Processes: The Case of Swedish Regulatory Design
}

\author{
Maria Pettersson ${ }^{1, *}$ and Patrik Söderholm ${ }^{2}$ \\ 1 Department of Business Administration, Technology and Social Sciences, Law Unit, \\ Luleå University of Technology, Luleå SE-971 87, Sweden \\ 2 Department of Business Administration, Technology and Social Sciences, Economics Unit, \\ Luleå University of Technology, Luleå SE-971 87, Sweden; E-Mail: Patrik.Soderholm@1tu.se \\ * Author to whom correspondence should be addressed; E-Mail: Maria.Pettersson@1tu.se; \\ Tel.: +46-70-220-9911, Fax: +46-92-049-2195.
}

Received: 27 March 2014; in revised form: 30 July 2014 / Accepted: 1 August 2014 /

Published: 19 August 2014

\begin{abstract}
Industrial pollution accounts for a large proportion of global pollution, and in the European Union, an integrated pollution and prevention approach based on individual performance standards has been implemented to regulate emissions from industrial plants. Crucial for the assessment of the licensing conditions are the Best Available Technique (BAT) requirements, which should be set in accordance with the recently introduced Industrial Emissions Directive (IED). In this paper, we review and assess the licensing of industrial plants in one of the Member States, namely Sweden. Specifically, we discuss how the existing regulations (including the IED) manage to address potential trade-offs between important regulatory design issues, such as flexibility, predictability and the need to provide continuous incentives for environmental improvements. The analysis indicates that while the EU regulations provide flexibility in terms of the choice of compliance measures, in Sweden, it enters an existing regulatory framework that adds a lot of uncertainty with respect to the outcome of the licensing processes. An important challenge for the implementation of the IED is to implement performance standards that lead to continuous incentives to improve environmental performance in industrial sectors without, at the same time, adding new uncertainties. While standards ideally should be both flexible and predictable, achieving one of these criteria may often come at the expense of the other.
\end{abstract}


Keywords: industrial pollution; environmental regulation; performance standards; Industrial Emissions Directive (IED); Best Available Technique (BAT)

\section{Introduction and Aim}

Air pollution, in particular combustion products stemming from fossil fuels and biomass, is a major threat to human health and the environment [1,2]. Environmental impacts in the form of, for instance, acid rain, smog and respiratory illnesses, as well as global issues, such as climate change, need to be addressed in government policy-making. A significant proportion of global pollution originates from different industrial activities, which therefore need to be regulated to avoid or mitigate adverse human health and environmental impacts. The environmental regulation of industrial plants differs across countries in terms of tax policies and legal tools (e.g., licensing procedures) and their specific design and implementation. This is the case even if we restrict ourselves to the range of various legal actions available for industrial pollution control; the objectives and the motives underlying these regulations have also tended to change over time; $c f$. [1].

Ribeiro and Kruglianskas [3] argue that modern environmental regulation has come quite a long way since the "first generation" of end-of-pipe-solutions and technology standards were implemented in the 1960s (most notably in the USA). The "second generation" regulation has been characterized by market-based instruments, such as pollution charges and emission trading schemes. These instruments encourage, it is argued, the introduction of cost-effective pollution prevention measures, as well as the development of new pollution abatement technology [4]. The market-based instruments have largely constituted complements, rather than substitutes, to the already existing regulations. This is not the least bit valid in the case of the regulation of point-source pollution at industrial plants, for which individual licensing and standards have maintained an important role in environmental policy. Still, the flexibility provided by the market-based instruments in terms of the selection of pollution abatement measures has spurred an increased interest in how the licensing processes and standards can be designed and implemented in a more flexible, transparent and preventive way, so as to maintain strong incentives for improved environmental performance without comprising economic goals $[3,5]$.

Moreover, the design of the legal framework for regulating industrial pollution, in terms of its effectiveness in increasing environmental performance and the associated economic costs, has also been the subject of "considerable debate" in the economics literature over the past fifteen years [1] (p. 91). Much of this discussion has centered on the so-called Porter hypothesis [6,7], essentially stating that properly-designed environmental regulations will: (1) stimulate environmental innovation (the weak version of the hypothesis); and (2) increase not only the environmental performance, but also the economic performance (i.e., profits, productivity, etc.) of firms and industries (the strong version). In general, there is strong empirical support for the weak version of the Porter hypothesis [8], e.g., [3,9-13]. However, the empirical support for the strong version is much more limited, e.g., [14]. This paper does not provide an explicit test of the Porter hypothesis; instead, we address the issue of how environmental regulations should be designed to increase the probability of Porter outcomes. 
According to Porter and van der Linde, properly-designed environmental regulations "should adhere to three principles. First, they must create the maximum opportunity for compliance and innovation, leaving the specific approach to compliance to industry and not to the standard-setting agency. Thus, regulations should permit flexibility in the choice of specific measures to comply with the regulations. Second, the regulatory process "should leave as little room as possible for uncertainty at every stage." [7] (p. 110). Regulatory designs that provide the authorities with a substantial degree of discretion to interpret how the legislation should be put into practice (e.g., concerning the conditions for obtaining a license to operate), as well as a lack of timeliness in the licensing process both add to the uncertainty by reducing the predictability of the regulations. From the perspective of industrial firms, the timing of the repayment of loans and the need to make a profit on the invested capital tend to force a particular negotiating outcome and timetable. Third and finally, the environmental regulations should foster continuous environmental improvements rather than locking in any particular technology. In the licensing process, this often represents a key challenge for the authorities, since industrial plants may have few incentives to perform beyond the pre-determined standard (see Section 2.2).

The above Porter criteria have, together with past experiences of different regulations, influenced contemporary policy-making and implied an increased emphasis on flexibility, incentives and long-term predictability in the design of environmental regulations. In practice, this means a maintained interest in market-based instruments, but increasingly also an interest in more flexible versions of the traditional regulation (licensing) of industrial plants. For instance, in the European Union (EU), a more integrated pollution prevention approach based on individual performance standards has been endorsed, both in the so-called IPPC Directive [15] and in the more recent Industrial Emissions Directive [16], repealing the IPPC Directive as of January 1, 2014. Performance standards provide much more leeway to undertake cost-effective pollution prevention measures than do, for instance, technology standards [17].

In spite of these regulatory developments, though, the licensing of industrial plants has also been increasingly criticized. For instance, even though Sweden has complied with the IPPC Directive, the licensing procedure has been claimed to be unpredictable, subjective, time-consuming and to lack coordination across different levels of authority [18,19]. Given that the IPPC systems have been credited with a substantial degree of flexibility, this critique is somewhat of a paradox, and there is reason to examine more closely the relationship between the legal framework for polluting industries and Porter's above-mentioned three criteria for properly-designed regulatory instruments.

The aim of this paper is to evaluate the Swedish system for the environmental licensing of industrial plants, with a particular focus on the individual performance standards and the implementation of the Industrial Emissions Directive in relation to the concept of "properly designed" regulatory instruments. Specifically, we adopt an investor eye-view of the environmental regulations in Sweden and thus analyze to what extent these provide flexibility in the choice of compliance measures and create or reduce regulatory uncertainty concerning the license conditions (content and timing). The prospect for implementing standards that provide continuous incentives for improved environmental performance is also investigated. The analysis is primarily based on legal assessments, including juridical decisions and case law. It also builds on the notion that it is important to acknowledge that new regulatory 
approaches and frameworks do not enter a vacuum, but rather they encounter preexisting regulations, institutions and implementation practices (see further Section 2).

The Swedish case is useful for a number of reasons. In Sweden, the environmental licensing procedures for industrial plants are based on case-by-case assessments of environmentally hazardous activities. Still, the assessment and the resulting regulations and conditions (individual performance standards) rely heavily on the criteria outlined in the Environmental Code, including the precautionary principle and the requirements for Best Available Technique (BAT). The grounds for assessment under the Environmental Code correspond essentially to the requirements of the now superseded IPPC Directive, and, therefore, constitute Sweden's principal implementation of the system for integrated pollution prevention and control. In keeping with this approach, emissions to air, water and land, as well as other environmental impacts shall be considered together, and permit conditions in the form of emission limit values (based on BAT) shall be established. The aim of the system is to achieve a high level of environmental protection by preventing emissions and waste production and, where that is not possible, by reducing them to acceptable levels ( $c f$. [16] (Art. 1)). Thus, Sweden represents a Member State where the EU legislation is well integrated into the existing regulatory framework. At the same time, though, the Swedish economy is dependent on significant industrial sectors (e.g., pulp and paper, iron and steel, mining, etc.), and industry representatives frequently point to the long lead times and unpredictable licensing conditions in Swedish regulations, e.g., [20].

This Swedish focus complements the other articles in this special issue on "environmental law and sustainability". Section 2 provides some brief methodological remarks. In Section 3, we review the existing environmental regulations in Sweden and analyze how this fulfills Porter's criteria of flexibility and predictability. In brief, we argue that while the EU legislation provides flexibility in compliance measures, it enters an existing domestic regulatory framework, which adds a lot of uncertainty, e.g., in land use assessments and the scope of the licensing process. Section 4 discusses some findings from this legal assessment and highlights the difficulties encountered when implementing gradually more stringent performance standards over time. We argue that providing continuous incentives for environmental improvements (i.e., Porter's third criteria for a properly-designed regulation) could be difficult without reducing the predictability of the regulatory conditions.

\section{Theoretical Framework and Methodology}

\subsection{The Concept of License}

The verb to license commonly means "[t]o grant (a person) a license or authoritative permission to do certain things, e.g., to practice some trade or profession", or "[t]o allow liberty, free range, or scope to; to privilege, tolerate". [21]. In other words, to grant a license means to give permission to someone to do something that he or she would otherwise not be allowed to do and which for that reason requires some form of quid pro quo or is subject to conditions, e.g., that the person has reached a certain age or has certain capabilities, in order to prevent damage or to ensure the actor's competence. A license to conduct environmentally hazardous activities thus implies that the operator receives a permit to commence or modify an activity that per definition may cause harm to human health or the environment, which therefore needs to be assessed in advance and, thereafter, controlled. 
The license and the licensing process, including the substantive grounds for assessment, are legal features, i.e., a result of legalization that involves elements of obligation, precision and delegation [22]. Obligation in this sense means that the actors are legally bound by a rule or a set of rules and that their behavior with regard to these rules is under some kind of legal control, which expresses itself, e.g., in duties to evaluate, report and respect the terms for the activity. The element of precision refers to the manner in which the rules of conduct are formulated: the rules describe and define what the authorized conduct is (and what it is not). Delegation is here seen as an authorization commonly given to government agencies to interpret, apply and supervise the rules, $c f$. [22].

Licensing-i.e., to grant permission to conduct an activity that is defined as environmentally hazardous - is consequently a way of legally controlling (and giving guidance for) various human behaviors and (economic) activities, such as building houses or roads, extracting minerals or producing goods. The basic function for this legal instrument is not to prevent or avoid every activity that may cause harm to the environment, but to regulate it and make sure that all interests are considered [3]. The environmental licensing process is therefore complex, typically involving the application of a large number of rules, distributed among several different laws and levels of authority, as well as environmental impact assessments and consultations with various stakeholders. The conditions for the license are typically based on substantive legal rules, but can vary a great deal depending on both the nature of the activity and the characteristics of the selected site, as well as such factors as the operator's financial situation and the employment rate. This, in turn, impacts both the environmental effects, as well as the economic outcomes of the activity. The process can be lengthy, especially considering the possibility of appealing the decisions. It is, in short, a balancing act, with the overall aim of supporting sustainable development from an economic, social and ecological perspective.

\subsection{Methodology}

To evaluate the Swedish system for environmental licensing in relation to the principles of the Porter criteria, a qualitative study based on analytical jurisprudence, here defined as the study of the concept or nature of law, is applied to determine the substantive content of the relevant law, e.g., [23-25]. The main sources of law used, in addition to statutory texts, are preparatory works, juridical decisions (case law) and, to some extent, jurisprudential studies. The selection of juridical decisions is based on the following keywords: environmentally hazardous activity, best available technique, precautionary principle and location requirements. The examined decisions are primarily so-called "guiding decisions" from the Land and Environmental Court of Appeal. In order to determine if the Swedish environmental regulation is "properly designed" and thus has the capacity to provide room for flexibility, predictability and continuous incentives for improved environmental performance, the regulatory system (including the practical implementation of the rules) needs to be examined in its entirety, i.e., not only by establishing the existence of specific provisions.

This legal assessment is in part complemented by drawing on some lessons from the environmental economics literature, which addresses the issue of which incentives for environmental compliance are provided through different ways of designing pollution regulations, as well as implementing these regulations. Different types of regulations (e.g., limit values versus charges) involve different types of challenges for the regulating authorities, not the least of which is in terms of the balancing act between 
environmental and business performance. Industrial plants typically differ in terms of their abatement costs, and so-called plant-regulator information asymmetries are normally present [4]. In other words, plant owners normally know far better than the regulating authorities (i.e., the courts) what it will cost to abate emissions at the plant (and these often have very few incentives to reveal this information to the regulator). For this reason, it is important to implement regulations that provide flexibility to industrial plant owners in their choice of pollution control measures (i.e., Porter's third criteria).

The information asymmetries, though, also complicate the process of implementing licenses and standards and, thus, also, the prospects for achieving Porter's third criteria for properly-designed regulations. For instance, the continuous incentive effects of emission limit values (or other types of performance-based standards) could deteriorate over time as less costly abatement technologies are developed. For this reason, there is a need for a gradual tightening of these values, but in determining the new values, the regulating authorities require substantial knowledge on abatement costs. If the authorities underestimate the abatement costs, the limit values will be very stringent with potentially detrimental effects on the economic performance of industrial activity, while if these costs are underestimated, the limit values will be higher, but resulting in incentives that are too weak for plants to improve their environmental performance. In other words, the regulatory-firm information asymmetries make it difficult to implement standards that are both stringent, but also predictable from the point of view of the industrial plants, i.e., creating problems to fulfill Porter's second criteria emphasizing uncertainty reduction at every stage of the licensing process.

The remainder of this paper illustrates that these considerations are far from unimportant in regulating industrial pollution in the EU and Sweden, and they imply difficult trade-offs in achieving Porter's criteria for a properly-designed environmental regulation. Specifically, in Section 3, we review the existing legislation and analyze to what extent this provides room for flexibility and predictability. Flexibility concerns how the conditions of the license are set, not the least of which is the extent that they rely on technology prescriptions or on performance-based standards. Moreover, licensing conditions that permit firms to test different technological solutions over a certain probation period (before the final license is granted) also add to the flexibility of plant owners and increase the scope for combining environmental and economic outcomes [5]. Predictability is primarily investigated through case law, and we analyze to what extent the existing legislation provides clear guidelines for how to balance different interest, including the potential scope for different, more or less subjective, interpretations of the rules. The greater this scope is, the less predictable will be the licensing conditions. In addition, the timeliness (length) of the licensing process may also be unpredictable (and too long) if the legislation provides only meager guidelines on how to interpret the rules. For instance, it could provide stronger incentives for stakeholders to appeal previous decisions [26]. Unfortunately, there exist no aggregate data on the frequency of appeals in industrial licensing processes. However, our selection of court cases, we argue, tends to display a legal system facilitating and even encouraging appeals, due to the lack of clear guidelines in the legal text. Finally, in Section 4, we address the issue of how regulators should provide continuous incentives for environmental improvements (pollution reduction) and the prospects for achieving this in general and in Sweden, in particular. 


\section{Results from the Legal Assessment}

In this section, we review the environmental legislation governing the licensing of industrial plants in Sweden. Specifically, we provide brief step-by-step descriptions and then pause after each part to comment on each piece of legislation in the context of the Porter criteria of flexibility and predictability.

\subsection{Environmental License: Permit Requirements for Polluting Industries}

In Sweden, the rules on licensing and permit requirements for environmentally hazardous activities are set out in the Swedish Environmental Code (EC) [27]. The regulatory framework is further fleshed out by ordinances and prescriptions that are interpreted and applied by sectoral government authorities, county administrative boards or courts. The license is heavily based on individual performance standards, which allegedly allow for certain flexibility with regards to the individual activity. This is well in line with the first Porter criterion and, thus, provides leeway for industrial firms to choose the most efficient (least costly) industrial pollution control measures.

Industrial polluting activities are typically regarded as environmentally hazardous under Swedish environmental law [28]. The main consequence of the definition is the possibility of imposing a permit requirement for the activity: in accordance with the law, the government may issue prescriptions that it is prohibited to conduct the activity before a permit has been obtained. An important piece of legislation in this context is Ordinance (1998:899) on Environmentally Hazardous Activities and Health Protection (in particular, s. 5) [29]. The ordinance specifies which activities require a permit (the activities are designated A, B or C, mainly based on their respective environmental hazardousness; plants with the largest environmental impacts are labeled A-plants) and who is the licensing authority. A permit is also required for more profound changes in the activity, for example industrial production expansions that can be assumed to entail an increased environmental impact. What constitutes a larger change is thus determined through possible impacts; for smaller changes that will not cause a nuisance to peoples' health or the environment, a (new) permit is not required [29].

As a result of EU legislation, permits may be granted for a limited period of time [27] and [30] (pp. 478-479). However, Swedish environmental permits have traditionally been issued indefinitely, and although the possibility of reconsidering the permits has increased, they are still generally regarded as time-unlimited, also by the licensing authorities, albeit on certain conditions [8]. It should be clear that this can lead to only a few incentives to continuously improve the environmental performance of many industrial plants in the country; some plants may rely on old permits that are no longer binding for the operations.

\subsection{Substantive Rules for the Assessment}

The assessment of environmental licenses in Sweden is performed on the basis of an integrated system of legal principles, rules and processes contained in the Environmental Code: from the principles of precaution and "polluter pays", via substantive rules for environmental consideration, natural resource management and environmental quality standards, which are all interconnected in the EIA process, to a system of licensing, supervision and sanctions [30] (pp. 168-170). Hence, according to 
this "principle" of an integrated approach to environmental law, all aspects of an activity (e.g., pollution, use of chemicals, processing, waste management, etc.) should be assessed in context: "The licensing process and supervisory practices should create incentives for the operator to be ahead of the legal requirements" [30] (p. 169, authors' translation). This means that, in the licensing process, the permit authority is obliged to assess the whole activity in relation to the environment, including direct, indirect and even cumulative effects, to some extent. These effects (or consequences) are primarily accounted for in an Environmental Impact Assessment (EIA), which must be prepared by the operator and accompany the permit application. This integrated regulatory approach may add to a lack of predictability concerning the scope of the EIA, and below (in Section 3.2.1), we describe and comment on a court case in which this issue resulted in a lengthy and largely uncertain licensing process.

In order to limit the environmental impacts of a polluting activity, the permit authority is responsible for imposing certain conditions in keeping with [27] Ch. 16, s. 2, for example by stipulating plant specific emission limitation values based on the substantive rules of the Environmental Code. The backbone of these substantive rules are the general consideration rules, which constitute the main transposition of overarching environmental law principles and establish ground rules for all activities and measures in relation to the environment, including requirement rules, balancing rules and liability rules. Moreover, the activity's compliance with the Code's resource management provisions is also assessed in the licensing process insofar as the activity involves the use of land and water areas. Since June, 2013, polluting industries are also covered by Ordinance (2013:250) on industrial pollution [31], which constitutes Sweden's implementation of the IED.

\subsubsection{Environmental Consideration Rules}

The main requirement imposed on operators of polluting activities is to be cautious, i.e., to take the measures necessary to prevent, avoid or counteract the damage or nuisance to human health or the natural environment. The precautionary requirement, as it is expressed in Ch. 2, s. 3, of the Environmental Code [27], covers all activities and measures that may impact human health and the environment. The second paragraph of this section clearly reflects the precautionary principle: "These precautions shall be taken as soon as there is reason to assume that an activity or action may result in damage or harm to human health or the environment." The other requirements, including those connected to the possession or acquisition of necessary knowledge [27] (s. 2), the conservation of raw materials or energy [27] (s. 5) or the application of the principle of substitution [27] (s. 4), can therefore be regarded as specifications of different areas where precaution can/must be taken. With support of both s. 3 and s. 5 of the Code, it can, for example, be required of an operator to change the energy or heating system if the suggested solution implies undue risks for the environment, $c f$. [32].

For professional activities [33], it is furthermore mandatory to use the best possible technique [27] (s. 3). Under Swedish law, the technique requirement refers to the best possible, rather than the best available, technique. The term includes the technology used and the ways in which a plant is constructed, designed, maintained, operated and decommissioned. To be regarded as "the best possible", the technique should moreover be industrially possible to use in the relevant industry [34] (p. 17). Consequently, the assessment of what constitutes the best possible technique includes two criteria: (1) it must be operational (technical solutions on the experimental stage do not count); and (2) the cost 
for using the technology must be reasonable, based on general industry conditions and not on individual circumstances [30] (p. 232). This essentially corresponds to the BAT requirements of the IED:

IED, Article 3(10) [16]: "best available technique" means the most effective and advanced stage in the development of activities and their methods of operation, which indicates the practical suitability of particular techniques for providing the basis for emission limit values and other permit conditions designed to prevent and, where that is not practicable, to reduce emissions and the impact on the environment as a whole:

- "Techniques" includes both the technology used and the way in which the installation is designed, built, maintained, operated and decommissioned;

- "Available techniques" means those developed on a scale that allows implementation in the relevant industrial sector, under economical and viable conditions, taking into consideration the costs and advantages, whether or not the techniques are used or produced inside the Member State in question, as long as they are reasonably accessible to the operator;

- "Best" means most effective in achieving a high general level of protection of the environment as a whole [16].

Furthermore, the environmental requirements are applicable "to the extent it cannot be considered unreasonable [for the operator] to meet them" (s. 7) [27], implying that plant-specific issues and economic feasibility shall be taken into account in the assessment. The principle of "environmentally motivated" underpins this assessment of reasonableness: if the first step technique (A) has been objectively determined as "the best possible", the second step will be taken to assess if the marginal (environmental) benefit of using that technology exceeds the marginal costs of introducing it from the operator's point of view. Important to note here is that it is the state of the environment at the specific location that is crucial for any impairment of the requirements; if the area suffers from acidification, a trade-off where the initial requirement for a specific sulfur abatement technique is replaced is thus unlikely even if the costs for introducing the technology are considerable.

The issue of the scope of the integrated EIA in accordance with the Environmental Code came to the fore in the licensing process regarding the opening of a new iron ore mine in the North of Sweden. In May, 2010, a license to open a mine at Gruvberget in the municipality of Svappavaara was granted by the then Environmental Court (now the Land and Environmental Court) [35]. The license admitted permission for mining and processing a certain amount of ore annually. This decision was however appealed by the Swedish Environmental Protection Agency (SEPA) on the grounds that the assessment should have included both the new and the existing activities in the area. According to SEPA, it is unclear what was included in the Court's assessment and what is covered by the permit, for instance with regard to the disposal of waste rock at the existing landfill and of groundwater and surface water to the reservoir. SEPA therefore argued that: "it is clear that these issues have not been assessed in an appropriate manner and that there has been no comprehensive assessment of all of the licensed activities" [36] (p. 2) and that it is impossible to a make an assessment of the overall environmental impacts of the new mining operation and regulate it in an appropriate manner if interconnected activities, like the pelletizing plant, are not included in the assessment. 
The company had no objection to SEPA's argument for a more comprehensive and integrated assessment, but did not consider this to be the main issue in the case. Instead, the company argued that it was not only possible, but also more suitable to regulate the different activities separately; it is common that a processing plant serves several mines, and "there has never been any doubt that these activities both can and should be regarded as independent units with respect to assessment and authorization" [36] (p. 5).

The Environmental Court of Appeal began by noting that the main issue in the case is "whether the activity applied for is an independent activity that can be assessed and examined separately, as the company claims, or, if the existing plants have such links to the new activity that they should be regarded as one activity that should be considered jointly, as the Environmental Protection Agency alleges" [36] (p. 8). Thereafter, the Court concluded that the aim of the Environmental Code is to enable a comprehensive and integrated assessment of activities that impact the environment, e.g., by introducing legally binding principles and environmental consideration rules applicable to all environmentally impacting activities and measures. The activities in the mining case were considered by the Court to be both geographically and technically connected. For example, water from the new pit would be led to an existing reservoir not covered by the permit; additional noise pollution and air emissions would cause cumulative effects not covered by the permit; and there was no permit for the landfill for the waste rock. Hence, the Environmental Court of Appeal decided to set aside the judgment of the Environmental Court and reject the previous permit application. The company was forced, therefore, to submit a new license application covering the entire operations, including the processing plant. Overall, this delayed the final decision on the permit by about four years.

This case suggests that there is uncertainty with regards to what shall be included in the application for license in accordance with the Environmental Code; even different regulatory authorities may come to different conclusions on this matter. Although, in this case, it was found that the geographical and technical links between the activities were such that they should be assessed and regulated in a context, the legal position is far from certain. The Environmental Court of Appeal only establishes that an application for license must be "complete", i.e., appropriately delimited and covering all environmental impacts that may be caused by the activity. In specific cases, this provides little guidance in how to determine the scope of the EIA. With reference to the Porter hypothesis, the regulatory environment manifested in this case cannot be considered to fully adhere to the principles for a properly-designed environmental regulation; there are considerable uncertainties both with regard to what shall be included in the license application and what thus must be prepared for, as well as (partly as a result of this) regarding the time schedule for the licensing process.

\subsubsection{Specific Rules for Industrial Emissions}

Since June 18, 2013, the IED has been implemented in Swedish legislation, mainly through Ordinance (2013:250) on industrial emissions [31]. Like the IPPC, IED is based on the notion that pollution from industrial activities is a transboundary issue that needs to be addressed at the EU level [37] and aims to "ensure a high level of environmental protection and the improvement of environmental quality," [16] (Recital 44): "In order to prevent, reduce and as far as possible eliminate pollution arising from industrial activities in compliance with the "polluter pays" principle and the 
principle of pollution prevention", it has been considered necessary to establish a legal framework for the control of the main industrial activities [16] (Recital 2). The main features of the legal framework are the licensing process and the substantive requirements in this respect, most notably the more prominent role given to the concept of BAT, where the BAT conclusions will play a more obligating role in the licensing process compared to the IPPC Directive [38].

Like its predecessor, the IPPC, the IED prescribes an obligation for operators of polluting industries to hold a permit and lays down the grounds for the granting of a permit, as well as permit conditions. A permit is required for new, as well as for substantial changes in existing activity [16] (Articles 4(1), 5(1-3) and 14(1)). Substantively, the Member States are required to take the necessary measures to see to it that all appropriate preventive measures against industrial pollution are taken, including that best available techniques are applied, that energy is used efficiently and that no significant pollution is caused [16] (Art. 11). The permit shall include emission limit values for polluting substances, based on BAT conclusions, which are the main reference for setting permit conditions, as well as suitable emission monitoring requirements (e.g., [16] Recital 13). Since the IED is a mini directive, Member States are allowed to set stricter conditions than those described in the BAT conclusions, provided that such measures are compatible with the Treaties and the Commission has been notified [16] (Art. 14), [39].

Another basic element of the IED is the requirement to regularly reconsider, and update, permit conditions, so that they truly reflect BAT, taking into account technological development and progression [16] (Art. 19, Recital 21). Within four years of the publication of the BAT conclusions, all permit conditions for installations concerned must be reconsidered and updated to be in compliance with the directive [16] (Art. 21). This thus provides an opportunity to impose regulations that gives industrial plants incentives to continuously improve their environmental performance; in Section 4, we comment on this opportunity in more detail and highlight the difficulties in imposing such gradually more stringent requirements without creating additional uncertainties and excessive costs. How frequent new BAT reference documents are to be produced is not regulated by the directive; the Commission shall, according to Recital 13 [16], strive to update the documents within eight years after they have been published. However, the directive also recognizes the importance of flexibility and allows, under certain circumstances, emission limit values that deviate from BAT. Accordingly, the license authority may set emission limits that differ from those associated with BAT "in terms of the values, periods of time and reference conditions applied" if it can be shown, through monitoring that the emissions do not exceed the levels associated with the best available techniques [16] (Recital 15). It is, in other words, possible to set emission limit values based on other values than the BAT conclusions, for example with respect to other time periods. The use of such an alternative value may, however, not lead to increased emission levels, under normal operating conditions, than would have been the case if the BAT conclusions had been used as a reference.

The criteria for best possible technique, including BAT reference documents (BREFs) and BAT conclusions, are frequently applied by licensing authorities like the Land and Environmental Courts and assessed by the Land and Environmental Court of Appeal in guiding cases. BREFs describe applied techniques, present emissions and consumption levels, as well as techniques considered for the determination of BAT, emerging techniques and BAT conclusions for certain defined activities. BAT conclusions are the parts of the BREF documents that lay down what is considered the best available technique, including its applicability, associated emission limit values and monitoring aspects [40]. 
There appears to be a general consensus, both within industry and among authorities, that BAT requirements and BREFs are indicated in the licensing process for polluting industries, and were so already before the implementation of the allegedly stricter IED. The licensing authorities also seem to be in agreement that the general consideration rules in the Environmental Code, most notably s. 3 [27], are applicable in this process and may imply stricter requirements than what follows from EU law.

However, in recent court cases, not the least of which is from the Land and Environmental Court of Appeal, the assessment of what the best technique is seems to be primarily based on EU legislation. The possibility to impose stricter regulation was not used in any of the examined cases [41]. In a judgment from 2014 [42], concerning the conditions for air emissions of sulfur from an oil refinery, the Swedish Environmental Protection Agency (SEPA) appealed a partial judgment from the Land and Environmental Court at Nacka District Court because of (too) low emission limit values for the sulfur recovery plant. The case involved an application for license in accordance with the Environmental Code for extended and changed activity; the judgment from the Land and Environmental Court [43] was a partial (second) assessment concerning the trial period for air emissions of sulfur and volatile organic compounds (VOC). Regarding the VOC emissions, the Court terminated the trial period and decided on additional conditions for the activity, for example that annual measurements to quantify the emissions of VOC from the refinery shall form the basis for assessing improvement needs and that vacuum valves shall be installed on all crude oil tanks. For the sulfur emissions, the Court concluded that, in accordance with the IED, the licensing authority shall set emission limit values that ensure that emissions under normal operating conditions do not exceed the emission levels associated with BAT according to the BAT conclusions. The Court found no support in the investigation that indicated that the future BAT conclusions also would include extraordinary events, like malfunctions and poorer accessibility. Hence, the company's proposal for the limit value for the recycling rate, where the lowest recycling rate includes typical deviations from normal operating conditions, were found acceptable, and the Court determined that the recycling rate, based on the input of sulfur to the recovery plant and the output of sulfur to the tail gas facility would amount to $98.5 \%$, calculated as a monthly average. The condition is considered fulfilled if the limit value is met for at least ten months in a year.

In the appeal, SEPA argued that according to the current BREF document, BAT for the recycling rate for sulfur recovery plants ranges between $99.5 \%$ and $99.9 \%$ and that the eight best facilities have a performance of $99.8 \%$ or more, including accessibility. In relation to the IED, SEPA pointed out that, since the IED is a minimum directive, Member States have the opportunity to invoke stricter rules and that no amendments in the general consideration rules thus will be made as a result of the Directive. Furthermore, to catch operational malfunction and similar incidents, the Swedish licensing system relies on: (1) probation for the permit; and (2) flexibility in the permit conditions, e.g., by letting the condition apply for a longer period of time. With regard to this, SEPA argued that, since the condition set by the Court did not encompass the sour gas that is flared in the case of operational malfunction, a recovery rate of $98.5 \%$ is too low, not the least of which is in consideration of the fact that the condition is deemed fulfilled if the limit values are met in ten out of twelve months. In conclusion, SEPA did not consider that the condition reflected the "best available technology" according to the Swedish rules and suggested an increase in the recycling rate to $99.1 \%$ or $99.2 \%$. The company objected to this, arguing that: "EPA's opinion and references to the BAT conclusions go beyond what the legislature intended and what is environmentally justified and reasonable to 
require" [42] (p. 5). SEPA's requirement was considered unreasonable since: (1) the current levels were in keeping with BAT; and (2) it would require large investments that could not be considered environmentally motivated.

The Environmental Court of Appeal found that the sulfur recovery plant indeed fulfilled the requirements under current BREF documents and that there were no compelling EU legal requirements to tighten the current conditions. However, the Court recognized that the rules of the Environmental Code may imply more stringent requirements with regard to the establishment of best possible technique and that an assessment pertaining to this therefore was necessary. To obtain updated information about different technical solutions, the draft for new BREF's for refineries [44] was considered in this assessment. In assessing the level of requirements that could apply, the Court noted that the company had agreed to SEPA's claim that the condition should relate to efficiency rather than recycling rate. Since the calculations therefore include also emissions from the sour gas flaring, the condition will comprise also abnormal operating conditions. Moreover, since even a short period of disruption in the operation of the sulfur recovery plant may temporarily greatly impair the efficiency and also result in an increase of sulfur emissions, the court found that very strict requirements on the efficiency could be justified. However, based on the fact that the total emissions of sulfur from the plant also were limited by another condition, according to which the total emissions of sulfur may not exceed 250 tons per year, and which would also govern the emissions from the recycling plant, the Court decided that the emission limitation value suggested by the company and established by the licensing authority was in fact BAT and, hence, sufficient.

On the one hand, the outcome of this case indicates that the environmental regulations at least partially satisfy Porter's criteria; the application of the regulatory framework leaves room for the company to make decisions in terms of compliance measures and technology selection. On the other hand, there still remains uncertainty both in terms of what can be considered as part of the BAT conclusions and the possibilities to impose stricter requirements as a result of the general rules of consideration in the Environmental Code. The Court's decision in the oil refinery case gives no clear guidance in these respects; on both issues, the Court merely concludes that, in practice, the emission ceiling in the overall conditions will imply sufficiently stringent demands on both the recovery rate and the availability for the sulfur recovery plant.

The issue of BAT requirements and BREF documents versus the Environmental Code's best possible technology was also subject to assessment in another judgment from 2014 [45]. The case concerned an application for a permit to increase the production of bleached kraft pulp by around $18 \%$ and cardboard production by around 14 percent. The increased production would lead to increased emissions to the air of, e.g., sulfur, due a transition from fossil fuels to heating with pitch oil. The Land and Environmental Court approved the company's environmental impact assessment and found that the activity also otherwise met the substantive requirements of the Environmental Code and that a license in principle thus could be granted. The main issue in the case was therefore on which conditions the activity should be permitted. Here, two of the referral bodies, SEPA and the County Administrative Board (CAB), were of a different opinion than the company and suggested prolonged probation and a stricter formulation of some of the proposed conditions. Regarding dust emissions to air from the biomass boiler and the lime kiln, the Court considered the levels claimed by the company 
to be on the high side in relation to the best possible technique and decided to support the (stricter) requirements suggested by SEPA and $\mathrm{CAB}$.

The company appealed the judgment regarding the condition of the dust content in flue gases from the biomass boiler and argued that, although the Court's stance is seemingly clear, there are significant uncertainties behind its reasoning. The contested condition was expressed as follows: the dust content in the flue gases from biomass boiler P12 may not exceed $50 \mathrm{mg} / \mathrm{m}^{3}$ at six percent $\mathrm{O}_{2}$, calculated as annual mean and limit values. The company called for an increase of the value to $75 \mathrm{mg} / \mathrm{m}^{3}$ at $6 \% \mathrm{O}_{2}$ [46] on the basis that all emission levels values are in line with the specified BREF document and that the contested condition is significantly lower than what has been imposed for comparable units at other mills in recent times. According to the company, it would not be possible to uphold the permitted production if the suggested condition remains; new investments would be necessary. The $\mathrm{CAB}$ acknowledged that the company may have to complete the current abatement system to meet the suggested condition, but did not consider this to be unreasonable or out of the ordinary in consideration of the production increase. In fact, the $\mathrm{CAB}$ even suggested a tightening of the contested condition. SEPA stated that the suggested emission level should be regarded as BAT, based on, among other things, the records of the company's previous emissions.

The Land and Environmental Court of Appeal stated that the company in 2013 completed a renovation of the biomass boiler resulting in lower dust emissions, implying that the proposed condition could be upheld. According to the Court, the argument that the dust emissions increase rapidly at a specific flue gas flow was not considered to motivate imposing a lower emission value, although it may be justified to allow for some margin to avoid that temporary overloads lead to exceeding of the condition. The suggested emission limit value was therefore considered sufficient in this respect, and the Land and Environmental Court of Appeal rejected the appeals.

Furthermore, in this case, BAT was primarily determined on the basis of the BREF documents for the particular activity, but with a much clearer assessment based on the substantive rules of the Environmental Code. In conformity with the Land and Environmental Court, the Superior Court balances the environmental requirements with what can be considered environmentally motivated in each individual case and arrives at a solution based on both what is technically possible and economically feasible. Emphasis is also put on the possibilities for the company to affect the emissions by the choice of fuel type, and the renovating of the biomass boiler is taken into account.

Pursuant to the IPPC/IED system, it is furthermore possible to deviate from the BAT conclusions if the application of these levels would lead to disproportionately high costs compared to the environmental benefits, as a result of the installation's geographical location or environmental or technical conditions [16] (Art. 15(4), Recital 16). Furthermore, those deviations may only be granted on the condition that no significant pollution is caused and that a high level of environmental protection is still achieved.

The meaning of the IED on the issue of the exceptions for "abnormal conditions" was subject to assessment by the licensing authority in a case related to conditions for dust emissions at a cement plant [47]. Based on the new directive, the Land and Environmental Court considered it necessary to change the suggested conditions. The main issue was the interpretation of the exception for "abnormal operating conditions". The suggested condition for dust emissions from the cement kilns included an exception for abnormal operation that was feared to counteract the purpose of the exception as it is 
expressed in the directive; the formulation of the condition was considered too imprecise and to lead to a situation where every emission deviation is seen as an example of abnormal conditions. The Land and Environmental Court thus reformulated the condition to the effect that also emissions from coolant gas were included. The company appealed the judgment to the Land and Environmental Court of Appeal [48], arguing that emissions from a separate filter for the purification of coolant gases are not possible to calculate according to the current formulation of the condition where the dust emissions are normalized at an oxygen level of ten percent. The Court began by noting that, since the entry into force of the Ordinance on industrial emissions, the licensing authority shall use emission limit values and other precautions listed for the activity in relevant BREF documents as a basis for its assessment. Thereafter, the Land and Environmental Court of Appeal concluded that it is not technically possible for the company to comply with the condition as it has been formulated by the Land and Environmental Court and arrived at the conclusion that the emissions of coolant gases should not be regulated as prescribed by the condition. The condition was changed in the way suggested by the company. Additional adjustments on account of the existing BREFs were not considered necessary.

The Swedish implementation of the IPPC model in general and the requirement for the best available technology in particular certainly seem to be comprehensive; the licensing authorities comply with both the BAT conclusions from the BREF documents and leave the door open for stricter requirements in accordance with national law, if that should be considered necessary. In specific cases, the Swedish courts have chosen to lean heavily on the BREF documents in determining BAT, and there are thus few (if any) attempts to go beyond these requirements.

\subsubsection{Legal Bases for Land Use}

The licensing process does however include more assessment criteria than pollution prevention via individual performance standards. A very important part of the Swedish licensing process involves the siting and access to land and water areas. Here, the starting point for the assessment is that "priority shall be given to use that promotes good management from the point of view of public interests" [27] (Ch. 3, s. 1). The basic resource management provisions thus provide guidance for conflicts of interests regarding the use of land. The rules also include specific land uses that are of particular interest (from a public perspective) and which therefore are subject to some degree of "protection", where activities that could significantly damage or significantly hamper the intended land use can be hindered. Land and water areas that contain valuable substances or materials should, for example, "as far as possible" be protected against activities that can "significantly hamper" the extraction of these substances or materials [27] (Ch. 3, s. 7). If the area is considered of national interest for some purpose, it "shall" be protected. When conflicts over land use arise, for example if an area is of national interest for more than one purpose, the guiding principle is that priority shall be given to the purpose that best promotes sustainable development [27] (Ch. 3, s. 10).

Overall, the rules are very generally formulated and the discretionary space extensive. With reference to the principles for properly-designed environmental regulation [7], the implication of this for the efficiency of the licensing process is potentially significant. While the rules on BAT and the BREF documents provide relatively clear indications regarding what can be expected, for example in terms of emission limits and, thus, conditions for permitting, the assessment under these rules can be performed 
on widely divergent inducements, leading to increased uncertainty regarding both the outcome of the licensing process and its duration; e.g., [26], [49] (p. 49), [50] (pp. 45-46), [51] (pp. 224-225). The ambiguity of the provisions also risks counteracting the sustainability objective. The guidance in terms of how to manage conflicting interests, especially regarding conflicting national interests, is scant, and the rules are formulated to steer away from, rather than to promote, the designated interests. As a result, the rules' governing function as a tool for sustainable development is almost negligible.

The general rules on land use as described above constitute the national spatial planning in Sweden. In addition to an assessment in accordance with these rules, the licensing process also includes assessments and decisions according to local-level spatial planning. Here, the system is characterized by a municipal planning monopoly under which the municipalities have the responsibility to, within the framework of the Planning and Building Act, decide if and when to plan for certain activities and on what basis. The County Administrative Board has some influence over the planning process through its position as the state representative for national interests, although to a limited extent; the Board cannot, for example, initiate, enforce or take over the planning. Industrial activities typically require preparation and adoption of zoning plans (e.g., for certain buildings and facilities), assignment of land for the purpose (e.g., for mining operations), as well as building permits. This, in turn, should conform to the comprehensive plan for the area, which is also established by the municipality.

Although the licensing in accordance with the Environmental Code is largely separated from the permitting process under the Planning and Building Act, the planning system thus has a considerable impact on the licensing process as a whole; without municipal consent, it is virtually impossible to commence activities. In accordance with this, the licensing authority also typically places great importance on both the activity's conformity with the spatial planning and on the opinion of the municipality, $c f$. [49] (p. 64). For certain types of facilities, amongst other larger polluting industries, the municipality also has the right of veto, making their opinion de facto decisive.

Even though the planning process is largely detached from the environmental licensing process, an evaluation of the licensing process as a whole in relation to Porter's concept of properly-designed environmental regulations must include all necessary permits and associated processes. In relation to the legal system for land use and spatial planning, the system may be viewed as holding certain flexibility, but at the same time, the current procedure probably represents a significant institutional barrier to a licensing process that is characterized by predictability. The substantial municipal influence and scope for discretion, together with a serious lack of comprehensive control over the planning process, leaves considerable room for uncertainty with respect to, primarily, the duration of the licensing process as a whole.

\subsubsection{Lex Specialis}

According to the lex specialis maxim for the interpretation of the law, special law takes precedence over general law. This means that, for many polluting industries, such as the mining industry, the waste industry or the forest industry, the Environmental Code, as a general law, is only part of the legal framework that controls the activities. The main laws here are constituted by sectoral legislation that applies in parallel to the Environmental Code on the basis of lex specialis. More specifically, for the Swedish licensing process, the principle implies that the trial of the activity is made both according 
to special law and general law, which partly results in environmentally hazardous activities (e.g., polluting industries) becoming subject to a double trial, but also in that the environmental assessment in some cases is restricted to include only the environmental standards set by special legislation. Different types of activities are thus subjected to different (environmental) requirements depending on whether (and how) environmental considerations are addressed by the special legislation. For polluting industries, such as mining or waste incineration plants, the environmental assessment in accordance with the Environmental Code thus constitutes only a portion of the requirements and assessments relating to the activity in its entirety.

\section{Concluding Discussion}

The Swedish licensing system for polluting industries is (partly) based on the IPPC/IED approach and offers the flexibility, as well as the regulatory constraints necessary to fulfill one of the criteria for "properly-designed" environmental regulation as presented by Porter and van der Linde [7]. Specifically, the licensing process is performance-based [52], which theoretically would imply that the system is also comparatively cost-effective and that it will promote environmental performance and innovation. Moreover, the legislation provides room for the use of probation periods, which give industrial plant owners some dynamic flexibility to evaluate and test different technological solutions. However, such probation periods do not appear to be implemented very consistently (see further below).

The licensing process is, though, also affected by other substantive rules, as well as additional laws and licensing requirements that could compromise the intended function of the system. At a general level, these rules and their implementation violate Porter's criterion of predictability on the part of industrial plant owners. Specifically, our court cases show that the legislation is often unpredictable with respect to the scope of the integrated environmental assessment and to some extent regarding the way in which BAT requirements are interpreted. In the first of these cases in particular, the legal rules provide very vague guidelines for how to assess specific cases, and this also provides room for appeals and lengthy licensing processes. Moreover, while the assessment and conditions established in accordance with the general consideration rules are based on, for instance, the precautionary principle and BAT requirements, the land use assessment and the planning process have different overtones. The statutory guidelines for the use of land and water areas primarily aim to provide guidance in the assessment of conflicting interests with a starting point in national interests for resource allocation and use. The rules are deliberately vague; one could argue that they have been formulated so as to provide flexibility in the interest of both societal development and environmental protection over time. However, legal rules should also aim to clarify "what applies" in a particular situation. The uncertainty resulting from the application of these rules with respect to what interests are protected or prioritized in specific cases could be questioned in light of the fundamental requirement of legal certainty. Again, this makes the outcome of the application of the rules difficult to predict and may lead to lengthy licensing processes due to appeals.

The planning system exhibits similar characteristics; despite its professed purpose to promote social development with equal and good living conditions, as well as sustainable development, the room for discretion left by the substantive provisions in the Planning and Building Act carries the risk of diluting these ambitious goals. In this sense, the spatial planning system is also a source of uncertainty 
that risks being incompatible with a licensing process that is underpinned by a "properly-designed" environmental regulation.

The above also indicates that designing regulations that are both flexible and predictable, while at the same time providing continuous incentives for environmental improvements (a la Porter) is a difficult task and is likely to involve important trade-offs. The difficulties involved in deciding upon specific emission limit values for individual plants are an illustration of this, as it may hamper the long-term stability and predictability of the regulations (e.g., due to the discretion of the courts). Similarly, due to firm-regulatory information asymmetries, the updating of the BREF-requirements at the EU level will likely be a difficult, uncertain and time-consuming process. If the standards are set too strict, this could have important economic repercussions for the affected industries, and if they are too lax, there would be little incentive to further improve environmental performance at the plant level. In the latter case, performance standards are likely to perform worse than market-based instruments. The reason is that in the former situation, the plant owners will have no incentive to perform beyond the pre-determined limit value, while market-based instruments, such as emission charges or markets for tradable allowances, induce plant owners to conduct low-cost abatement beyond the current level (since this reduces charge or allowance payments).

Moreover, Sweden has the opportunity to set emission limit values that are stricter than the BREF requirements. Our assessment of case law shows that this is something that is being seriously considered by the courts, but so far, the BREF values (based on the IED) have had an important influence on the actual licensing conditions. Again, while this "praxis" (if pursued also in the future), could be said to improve the predictability of the regulations, it could also provide a lost opportunity in encouraging continuous improvements in environmental performance. In a static setting, the uniform BREF requirements can provide both predictability and permit flexibility in the choice of compliance measures, but in order to improve environmental performance over time, the regulator needs improved information and knowledge about the abatement costs at each individual plant. While case-by-case regulation will improve the prospect for imposing gradually more stringent standards, our case studies show that this also risks creating uncertainty about the licensing conditions and the timeliness of the process.

Bergquist et al. [5] show that during the 1970s and 1980s, the Swedish authorities were able to implement gradually stricter emission limit values for industrial plants (e.g., in the pulp and paper and metal smelting industries), without this having serious negative impacts on profits and industrial productivity. This required, though, substantial investment among regulatory and other government authorities (e.g., SEPA) in know-how on industry-specific pollution abatement technology to bridge information asymmetries between plant owners and the regulating authorities. The use of probation periods was also used consistently, permitting plants to combine productive investments with pollution abatement measures. No similar or related strategy for addressing firm-regulator interactions and the balancing act between environmental and economic outcomes over time appears to exist in the current regulatory system, neither at the EU level nor in Sweden. For instance, the regulatory know-how on industrial processes is much less developed [5], and the use of probation periods is not used consistently.

While Sweden is an apt example of the regulatory challenges involved in addressing industrial pollution, these challenges are generic and apply to all Member States. In sum, while Porter and van der Linde [7] assert that properly-designed environmental regulations should be flexible, predictable 
and provide incentives for continuous improvement in environmental performance, these criteria may often be difficult to achieve at the same time. Case-by-case assessments of individual industrial plants based on the IED (and the BREFs attached to this Directive) provide flexibility in terms of the choice of pollution abatement technologies, but implementing these while leaving little room of uncertainty is far from straightforward in practice. In the EU, including Sweden, significant uncertainties are added: (1) when the industry-specific performance standards (in the BREFs) should be revised over time; as well as (2) when the EU legislation enters an existing domestic regulatory framework (e.g., including land use assessments, BAT interpretations and the call for integrated environmental assessments).

\section{Acknowledgments}

Financial support from the Swedish Environmental Protection Agency and the Hjalmar Lundbohm Research Centre (HLRC) is gratefully acknowledged, as are helpful comments from three anonymous reviewers. Any remaining errors or shortcomings are, however, solely the authors' and should thus not be attributed to any other individuals or institutions.

\section{Author Contributions}

Overall, the authors have contributed equally to this work. However, the legal analyses have primarily been made by Pettersson.

\section{Conflicts of Interest}

The authors declare no conflict of interest.

\section{References and Notes}

1. Testa, F.; Daddi, T.; de Giacomo, M.R.; Iraldo, F.; Frey, M. The effect of Integrated Pollution Prevention and Control regulation on facility performance. J. Clean. Prod. 2014, 64, 91-97.

2. Myers, S. Global Environmental Change: The Threat to Human Health; Worldwatch Institute: Washington, DC, USA, 2009.

3. Riberio, F.M.; Kruglianskas, I. Improving environmental permitting through performance-based regulation: A case study of Sao Paolo State, Brazil. J. Clean. Prod. 2013, 46, 15-26.

4. Goulder, L.H.; Parry, I.W.H. Instrument Choice in Environmental Policy. Rev. Environ. Econ. Policy 2008, 2, 152-174.

5. Bergquist, A.-K.; Söderholm, K.; Kinneryd, H.; Lindmark, M.; Söderholm, P. Command-and-Control Revisited: Environmental Compliance and Technological Change in Swedish Industry 1970-1990. Ecol. Econ. 2013, 85, 6-19.

6. Porter, M.E. America's Green Strategy. Sci. Am. 1991, 246, 168-168.

7. Porter, M.E.; van der Linde, C. Toward a New Conception of the Environment-Competitiveness Relationship. J. Econ. Perspect. 1995, 9, 97-118. 
8. In this context, it may be mentioned that the Land and Environmental Court of Appeal describes the Swedish system for environmental permits as follows: "With the Swedish system, where the license has an extensive legal effect and a validity that normally is not time-limited, reviewing the permit conditions is a rather extensive process". (Opinion by the Land and Environmental Court of Appeal on the proposal for a new Directive on industrial emissions). (Author's translation).

9. Jänicke, M. Ecological modernization: New perspectives. J. Clean. Prod. 2008, 16, 557-565.

10. Lanoie, P.; Laurent-Luccetti, J.; Johnstone, N.; Ambec, S. Environmental Policy, Innovation and Performance: New Insights on the Porter Hypothesis. J. Econ. Manag. Strategy 2011, 20, 803-842.

11. Ambec, S.; Cohen, M.A.; Elgie, S.; Lanoie, P. The Porter Hypothesis at 20. Discussion Paper, Resources for the Future, RFF DP 11-01, 2011.

12. Ford, J.A.; Steen, J.; Verreynne, M.-L. How environmental regulation affect innovation in the Australian oil and gas industry: Going beyond the Porter Hypothesis. J. Clean. Prod. 2014, in press.

13. Söderholm, K.; Bergquist, A.-K. Growing Green and Competitive: A Case Study of a Swedish Pulp Mill. Sustainability 2013, 5, 1789-1805.

14. Brännlund, R.; Lundgren, T. Environmental Policy without Costs? A Review of the Porter Hypothesis. Int. Rev. Environ. Resour. Econ. 2009, 3, 75-117.

15. Directive 2008/1/EC of the European Parliament and of the Council of 15 January 2008 concerning integrated pollution prevention and control.

16. Directive 2010/75/EU of the European Parliament and of the Council of 24 November 2010 on industrial emissions (integrated pollution prevention and control).

17. Silvo, K.; Jouttijärvi, T.; Melanen, M. Implications of regulation based on the IPPC-directive-A review of the Finnish pulp and paper industry. J. Clean. Prod. 2009, 17, 712-723.

18. Aaro, L-E.; Ferbe, A.; Evrell, L.; Fahlberg, C.; Sundelin, B.; Sterte, J.; Waplan, K-A.; Bennerdt, S.; Bengtsson, U.; Hedlin, J.; et al. Debatt: Ge gruvorna chansen. Dagens Industri, 30 January 2012.

19. Pettersson, M.; Oksanen, A.; Petrov, V.; Mingaleva, T. License to Mine: A comparison of the scope of the environmental assessment in Sweden, Finland and Russia. 2014, unpublished work.

20. Ramböll Management Consulting. Undersökning av genomförandetider och framtida resursbehov för projekt med miljöpåverkan; Report for the Confederation of Swedish Enterprise, Stockholm, Sweden, 2011. Available online: http://regelbloggen.nnr.se/wp-content/uploads/2012/03/RapportUnders\%C3\%B6kning-av-framtida-resursbehov-.pdf (accessed on 14 August 2014). (In Swedish)

21. The Oxford English Dictionary. Available online: http://www.oed.com (accessed on 19 February 2014).

22. Abbott, K.W.; Keohane, R.O.; Moravcsik, A.; Slaughter, A.-M.; Snidal, D. The Concept of Legislation. Int. Org. 2000, 54, 401-419.

23. Austin, J. The Province of Jurisprudence Determined; Rumble, W.E., Ed.; Cambridge University Press: Cambridge, NY, USA, 1832.

24. Kelsen, H. The Pure Theory of Law and Analytical Jurisprudence. Harv. Law Rev. 1941, 55, 44-70.

25. Hart. H.L.A. The Concept of Law, 2nd ed.; Oxford University Press: Oxford, UK, 1994.

26. Söderholm, P.; Ek, K.; Pettersson, M. Wind Power Development in Sweden: Global policies and local obstacles. Renew. Sustain. Energy Rev. 2007, 11, 365-400.

27. Swedish Code of Statutes. Swedish Environmental Code 1998:808, 1998. Available online: http://rkrattsdb.gov.se/SFSdoc/98/980808.PDF (accessed on 15 August 2014). 
28. According to Ch. 9, s. 1 in the Environmental Code [27] the following defines as environmentally hazardous activity: "1. the discharge of wastewater, solid matter of gas from land, buildings or structures onto land or into water areas or groundwater; 2. any use of land, buildings or structures that entails a risk of detriment to human health or the environment due to discharges or emissions other than those referred to in subsection (1) or to pollution of land, air, water areas or ground-water; or 3. any use of land, buildings or structures that may cause nuisance to the surroundings due to noise, vibration, light, ionizing, non-ionizing radiation or similar impact".

29. Government Office of Sweden. Ordinance (1998:899) on environmentally hazardous activities and health production.

30. Government Office of Sweden. Prop. 1997/98:45, part I. In Miljöbalk; Parliamentary Press: Stockholm, Sweden, 1997.

31. Government Office of Sweden. Ordinance (2013:250) on Industrial Emissions; Parliamentary Press: Stockholm, Sweden, 2013.

32. Judgement of the Land and Environmental Court of Appeal 2003-06-10 in case M 3200-01

33. To qualify as "professional", the activity must have a certain scale, duration, be conducted for profit, and be of independent character.

34. Government Office of Sweden. Prop. 1997/98:45, part II. In Miljöbalk; 1997. Available online: http://www.regeringen.se/content/1/c4/13/52/54b9e750.pdf (accessed on 14 August 2014).

35. Judgment of the Environmental Court 2010-05-10 in case M 1471-08.

36. Judgment of the Environmental Court of Appeal 2011-03-10 in case M 4866-10.

37. $C f$. Article 5 on the principle of subsidiarity and the principle of proportionality in the Treaty of the EU [53].

38. Government Office of Sweden. Prop. 2012/13:35. In Nya regler för industriutsläpp; 2012. Available online: http://www.regeringen.se/content/1/c6/20/19/94/ba96b554.pdf (accessed on 15 August 2014).

39. It can be noted here that the obligation to transpose the IED into national law is limited to provisions that represents a substantive change as compared to the earlier IPPC directives.

40. Art. 3(11) and (12) [16]. Official Journal of the European Union. Available online: http://eurlex.europa.eu/LexUriServ/LexUriServ.do?uri=OJ:L:2010:334:0017:0119:en:PDF (accessed on 15 August 2014).

41. In addition to the cited cases, the Court has decided on the same grounds in a large number of similar cases, for instance: M 1205-13, M 6909-12, M 8089-12, M 10479-12, M 335-11, and M 6936-03.

42. Judgement of the Land and Environmental Court of Appeal 2014-02-28 in case M 4407-13.

43. Judgement of the Land and Environmental Court 2013-04-10 in case M 2293-07.

44. European Commission. Best Available Techniques (BAT) Reference Document for the Refining of Mineral Oil and Gas. Final Draft (July 2013).

45. Judgement of the Land and Environmental Court 2013-02-21 in case M 335-11.

46. Judgement of the Land and Environmental Court of Appeal 2014-02-19 in case M 2544-13.

47. Judgement of the Land and Environmental Court 2013-13-26 in case M 4345-12.

48. Judgement of the Land and Environmental Court of Appeal 2013-11-15 in case M 3695-13. 
49. Pettersson, M. Renewable Energy Development and the Function of Law. A Comparative Study of the Legal Rules Related to the Planning, Installation and Operation of Windmills. Ph.D. Thesis, Luleå University of Technology, Luleå, Sweden, 16 December 2008.

50. Bengtsson, B. Speciell Fastighetsrätt Miljöbalken, 10th ed.; Iustus Förlag: Uppsala, Sweden, 2010.

51. Government Office of Sweden. Prop. 1985/86:3. In Lag om hushållning med naturresurser m.m; 1985. Available online: http://data.riksdagen.se/fil/6665C18D-3CF8-4122-B5DA-FDD3F5A844BD (accessed on 15 August 2014).

52. Coglianese et al. (2004) [54] defines a regulatory system as performance-based when performance is used as: " 1 . the basis for legal commands found in regulatory standards, 2 . a criterion for allocating enforcement and compliance resources, 3. a trigger form the application of differentiated (or tiered) regulatory standards, and 4. a basis for evaluating regulatory programs and agencies".

53. European Union. Treaty of the European Union. Off. J. Eur. Union 2010, 53, C 83. Available online: http://eur-lex.europa.eu/legal-content/EN/TXT/PDF/?uri=OJ:C:2010:083:FULL\&from=EN (accessed on 15 August 2014).

54. Coglianese, C.; Nash, J.; Omstead, T. Performance-based Regulation: Prospects and Limitations in Health, Safety and Environmental Protection. Regulatory Policy Program, Center for Business and Government, John F. Kennedy School of Government, Harvard University, Cambridge, MA, USA, 2002.

(C) 2014 by the authors; licensee MDPI, Basel, Switzerland. This article is an open access article distributed under the terms and conditions of the Creative Commons Attribution license (http://creativecommons.org/licenses/by/3.0/). 